\title{
ANALISIS PENGARUH KEPEMIMPINAN DAN KOMPENSASI FINANSIAL TERHADAP KEPUASAN KERJA KARYAWAN
}

\author{
Deni Wardani \\ Farrah Fauzia Jacub
}

\begin{abstract}
This research aimed to prove that leadership and compensation influence on job satisfaction at PT Pertamina Lubricants. Within this research, population research refers to employee at PT Pertamina Lubricants which is about 80 employees that already pass the probation time. Sample used about 30 respondents and data was taken by way of questionnaires.

The data collection is analyzed by Regression Analysis. The result of this analysis showed that $Y=3,474+0,321 \times 1+0,718 X 2$, and the determination coefficients is about $50,1 \%$. Byt that means, there are signification effect about Leadership and Compensation on Job Satisfaction.
\end{abstract}

Keywords: Leadership, Compensation, Job Satisfaction, Employees

\section{PENDAHULUAN}

Perkembangan teknologi yang semakin modern dan dinamis mendorong perusahaan untuk lebih kompetitif dalam menghadapi persaingan sat ini. Dalam hal ini perusahaan dituntut agar dapat menjalankan perannya dengan lebih baik dalam pencapaian tujuan dan meningkatkan kinerja perusahaan secara optimal. Selain menggunakan teknologi yang modern, perusahaan juga perlu memperhatikan pengelolaan dan pengkoordinasian sumber daya manusianya agar terjalin sinergi antara perusahaan dengan karyawan. Sumber daya manusia mempunya peranan penting baik secara perorangan maupun kelompok, dan sumber daya manusia merupakan salah satu penggerak utama atas kelancaran jalannya kegiatan perusahaan, bahkan maju mundurnya perusahaan ditentukan oleh keberadaan sumber daya manusianya itu sendiri. Untuk itu setiap perusahaan perlu memperhatikan dan mengatur keberadaan karyawannya sebagai usaha meningkatkan kepuasan kerja karyawan.

Pada dasarnya untuk memperoleh sumber daya manusia yang sesuai dengan kebutuhan diperlukan strategi untuk mengelola karyawan yang dimilikinya. Perusahaan harus memandang karyawan sebagai pribadi yang mempunyai kebutuhan atas pengakuan dan penghargaan, dan bukan sebagai alat untuk pencapaian tujuan perusahaan semata. Demikian perusahaan tidak hanya menuntut apa yang harus diberikan karyawan terhadap perusahaan, tetapi juga memikirkan apakah kebutuhan karyawan telah terpenuhi sehingga dapat merangsang timbulnya komitmen dan loyalitas yang dapat diberikan kepada perusahaan, dan dalam tingkat atau level tertentu akan mencapai titik dimana karyawan merasakan kepuasan kerja. 


\section{LANDASAN TEORI}

\subsection{Manajemen Sumber Daya Manusia}

Manajemen Sumber Daya Manusia (MSDM) mengacu pada desain dan penerapan system formal untuk memastikan penggunaan bakat manusia yang efektif dan efisien dalam rangka mencapai tujuan-tujuan organisasi. MSDM adalah kegiatan yang dilaksanakan untuk menarik, mengembangkan dan memelihara tenaga kerja yang efektif dalam sebuah organisasi (Daft, 2010).

Gambar 2.1 Proses Manajemen Sumber Daya Manusia
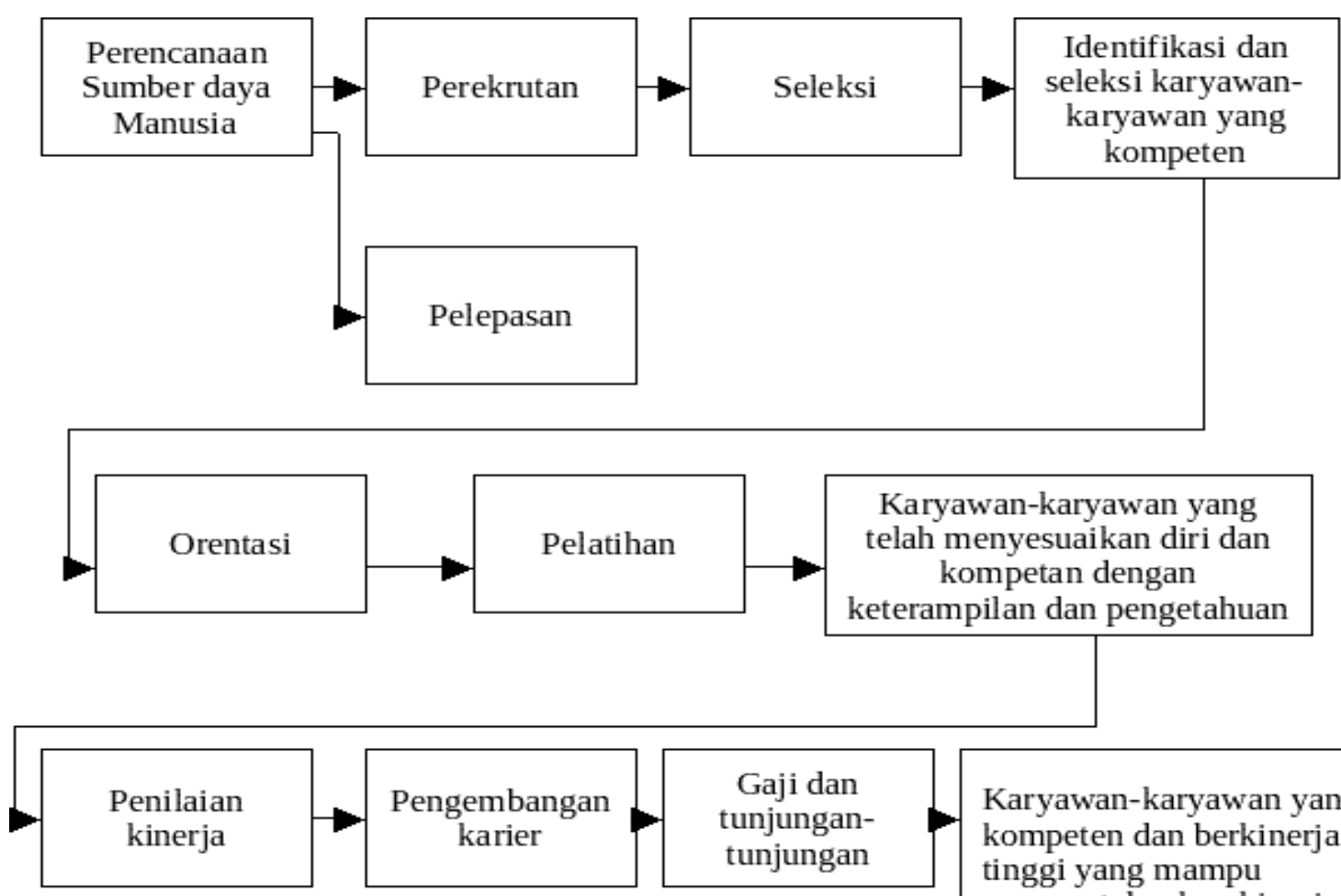

Karyawan-karyawan yang kompeten dan berkinerja tinggi yang mampu mempertahankan kinerja tinggi ini selama jangka panjang

Sumber: Stephen Robbins (2007)

\subsection{Keterkaitan Antar Variabel}

Hubungan antara kepemimpinan dan kepuasan kerja dalam teori jalur-sasaran yang dikemukakan oleh Evans (1970) dalam Robbins (2008) menyatakan terdapat kecenderungan bahwa kinerja dan kepuasan kerja berpengaruh secara positif bila pemimpin itu mengimbangi hal-hal yang kurang dalam diri karyawan atau dalam situasi kerja. Faktor-faktor lingkungan (struktur tugas, sistem otoritas, dan kelompok kerja) menentukan tipe perilaku pemimpin yang diisyaratkan sebagai pendukung agar hasil yang diberikan karyawan maksimal, sedangkan faktor karakteristik bawahan (lokus kendali, pengalaman, kemampuan pemahaman) menentukan cara karyawan menafsirkan lingkungan dan perilaku pemimpin itu. Jadi, teori tersebut menjelaskan bahwa perilaku pemimpin tidak akan efektif bila tidak sebangun dengan karakteristik bawahan dan melebihi struktur lingkungan itu sendiri. 
Analisis Pengaruh Kepemimpinan ...

\subsection{Penelitian Terdahulu}

Penelitian yang dilakukan oleh (Sari, 2009) tentang "Pengaruh Kompensasi dan Iklim Organisasi terhadap Kepuasan Kerja" membuktikan bahwa dari hasil penentuan urutan factor variabel kompensasi yang paling mempengaruhi kepuasan kerja adalah komponen tunjangan yang berbeda dari gaji bulanan.

Penelitian yang dilakukan oleh (Fauzan, 2012) dengan judul "The Influence of Compensation and Job Characteristics on Job Satisfaction" menyimpulkan bahwa secara parsial terdapat pengaruh yang signifikan antara kompensasi finansial dengan kepuasan kerja karyawan.

\subsection{Rerangka Pemikiran}

Untuk lebih memperjelas arah dari penelitian yang bertujuan untuk menunjukkan bahwa adanya hubungan antara kepemimpinan dan kompensasi yang mempengaruhi kepuasan kerja karyawan maka dalam penelitian ini dapat diambil suatu jalur pemikiran yang diterjemahkan dalam diagram struktur seperti pada gambar 2.2

Gambar 2.2. Rerangka Pemikiran

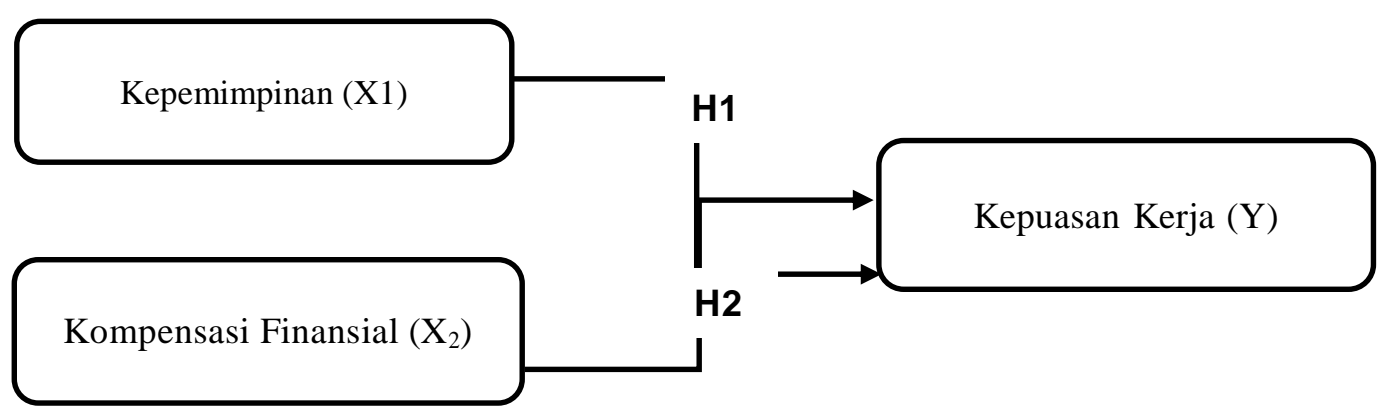

\section{METODE PENELITIAN}

Penelitian ini meneliti tentang manajemen sumber daya manusia yang berkaitan dengan kepemimpinan, kompensasi finansial dan kepuasan kerja. Adapun yang menjadi objek penelitian adalah karyawan PT. Pertamina Lubricants yang berlokasi di:

- Gedung Oil Centre, Lt. 5

- Jl. MH. Thamrin Kav.55 - Jakarta Pusat - 10350

- Penelitian ini dilakukan antara bulan Mei-Juli 2014.

Penelitian ini menggunakan pendekatan kuantitatif, dimana data-data yang bersifat kualitatif diterjemahkan ke dalam bentuk angka-angka kuantitatif agar dapat dianalisis menggunakan metode statistik. Hasil analisis statistik tersebut selanjutnya akan dipresentasikan kembali ke dalam bahasa kualitatif agar lebih mudah dipahami oleh pihak- pihak yang membutuhkannya. 


\section{ANALISIS DAN PEMBAHASAN}

Dalam penelitian ini yang menjadi populasi adalah karyawan pada PT Pertamina Lubricants sebanyak 80 karyawan yang tercatat sudah memiliki masa kerja lebih dari 2 bulan (melampaui masa percobaan).

Oleh karena populasi sudah diketahui, maka berikut perhitungan penentuan jumlah sampel yang dijadikan dasar pengambilan sampel dengan menggunakan rumus slovin:

$$
n=\frac{N}{1+n e^{2}}
$$

\section{Keterangan:}

$\mathrm{n}=$ ukuran sampel

$\mathrm{N}=$ ukuran populasi

e $\quad=\quad$ batas toleransi kesalahan $(95 \%)$

maka dapat diketahui jumlah sampel minimal yaitu:

$$
\begin{gathered}
n=\frac{80}{1+(80)(0.05)^{2}} \\
n=\frac{80}{1,2}=66.67 \text { dibulatkan menjadi } 67
\end{gathered}
$$

\subsection{Uji Validitas}

Pada tabel 4.1 di bawah ini hasil uji validitas penelitian diketahui bahwa indicatorindikator setiap variabel yang terdapat pada instrument penelitian ini adalah valid atau dapat digunakan untuk mengukur keseluruhan variabel yang akan diteliti.

Tabel 4.1. Hasil Uji Validitas

\begin{tabular}{|l|l|l|l|}
\hline Variabel & Pernyataan & $\begin{array}{l}\text { Pearson } \\
\text { Correlation }\end{array}$ & Hasil Uji \\
\hline Kepemimpinan (X1) & KP1 & 0.728 & Valid \\
& KP2 & 0.611 & Valid \\
& KP3 & 0.711 & Valid \\
& KP4 & 0.772 & Valid \\
& KP5 & 0.465 & Valid \\
& KP6 & 0.639 & Valid \\
& KP7 & 0.564 & Valid \\
\hline Kompensasi Finansial (X2) & KO1 & 0.738 & Valid \\
& KO2 & 0.703 & Valid \\
& KO3 & 0.746 & Valid \\
\hline Kepuasan Kerja (Y) & KO4 & 0.703 & Valid \\
& KK1 & 0.687 & Valid \\
& KK2 & 0.773 & Valid \\
& KK3 & 0.588 & Valid \\
& KK4 & 0.385 & Valid \\
& KK5 & 0.736 & Valid \\
& KK6 & 0.537 & Valid \\
\hline
\end{tabular}


Analisis Pengaruh Kepemimpinan ...

Hasil tabel 4.1 pengujian uji validitas menunjukkan bahwa keseluruhan indicator variabel kepemimpinan, kompensasi finansial, dan kepuasan kerja masing-masing memperlihatkan skor Pearson Correlation 0,385 s/d 0,773 lebih besar dari $r$ tabel. Oleh karena $\mathrm{N}=67$ maka $\mathrm{df}=\mathrm{N}-2=67-2=65$. Nilai $r$ tabel $=0,24(\mathrm{df}=65, \alpha=0,05)$. Hasil Pearson Correlation pada tabel diatas diketahui bahwa semua butir pernyataan memiliki nilai $r$ hitung $>r$ tabel sehingga semua pernyataan dikatakan valid.

\subsection{Uji Reliabilitas}

Pada tabel 4.2 di bawah ini dapat dilihat pengukuran hasil Uji Reliabilitas dalam penelitian ini adalah sebagai berikut:

Tabel 4.2. Hasil Uji Reliabilitas

\begin{tabular}{|c|c|c|c|}
\hline Variabel & Cronbach Alpha & N of Items & Hasil Uji \\
\hline Kepemimpinan (X1) & 0.759 & 7 & Valid \\
\hline Kompensasi Finansial (X2) & 0.685 & 4 & Valid \\
\hline Kepuasan Kerja (Y) & 0.689 & 6 & Valid \\
\hline
\end{tabular}

Dari tabel diatas, dapat diketahui bahwa semua pernyataan yang ada pada setiap variabel tersebut adalah reliabel. Hal tersebut ditunjukan dengan keseluruhan nilai Cronbach Alpha pada uji tersebut bernilai > 0,6. Hal ini menunjukkan bahwa setiap pernyataan yang digunakan sebagai alat ukur adalah reliabel dan dapat digunakan untuk penelitian selanjutnya.

\subsection{Uji Normalitas}

Pada penelitian ini cara yang digunakan untuk menguji apakah data terdistribusi normal atau tidak adalah dengan menggunakan uji One Sample Kolmogorov Smirnov dengan menggunakan taraf signifikansi sebesar 0,05.

Tabel 4.3. Hasil Uji Normalitas

One-Sample Kolmogorov-Smirnov Test

\begin{tabular}{|l|l|l|l|}
\hline & KEPEMIMPINAN & $\begin{array}{l}\text { KOMPENSASI } \\
\text { FINANSIAL }\end{array}$ & $\begin{array}{l}\text { KEPUASAN } \\
\text { KERJA }\end{array}$ \\
\hline $\mathrm{N}$ & 67 & 67 & 67 \\
Normal a, b b & 29.5075 & 17.5522 & 25.5522 \\
Parameters & 3.56487 & 1.94845 & 2.73187 \\
$\quad$ Mean & .145 & .164 & .151 \\
Std. Deviation & .087 & .134 & .119 \\
Most Extreme & -.145 & -.164 & -.151 \\
Absolute & 1.186 & 1.344 & 1.233 \\
Differences & .120 & .054 & .096 \\
Positive & & & \\
\hline
\end{tabular}




\begin{tabular}{|l|l|l|l|}
\hline Negative & & \\
Kolmogorov- & & & \\
Smirnov Z & & & \\
Asymp. Sig. (2- & & & \\
tailed) & & \\
\hline
\end{tabular}

a. Test distribution is Normal

b. Calculated from data.

Berdasarkan hasil pengujian normalitas residual, diketahui bahwa residual model persamaan regresi memiliki nilai Asymp. Sig $0.054 \mathrm{~s} / \mathrm{d}$ 0,120. > alpha 0,05. Maka $\mathrm{H}_{0}$ diterima, artinya sebaran nilai residual pada seluruh model persamaan regresi dinyatakan berdistribusi normal.

\subsection{Uji Multikolinieritas}

Penelitian ini menggunakan nilai Variance Inflation Factor (VIF) dalam Colinearity Statistics untuk menentukan ada atau tidak adanya gejala multikolinearitas. Hasil VIF yang lebih besar dari 10 menunjukkan adanya gejala multikolinearitas, sedangkan nilai VIF yang lebih kecil dari 10 menunjukkan tidak adanya gejala multikolinearitas. Hasil dari pengujian multikolinearitas dapat dilihat dalam tabel 4.4 berikut ini:

Tabel 4.4. Hasil Uji Mutikolinieritas

\section{Coefficients $^{\mathrm{a}}$}

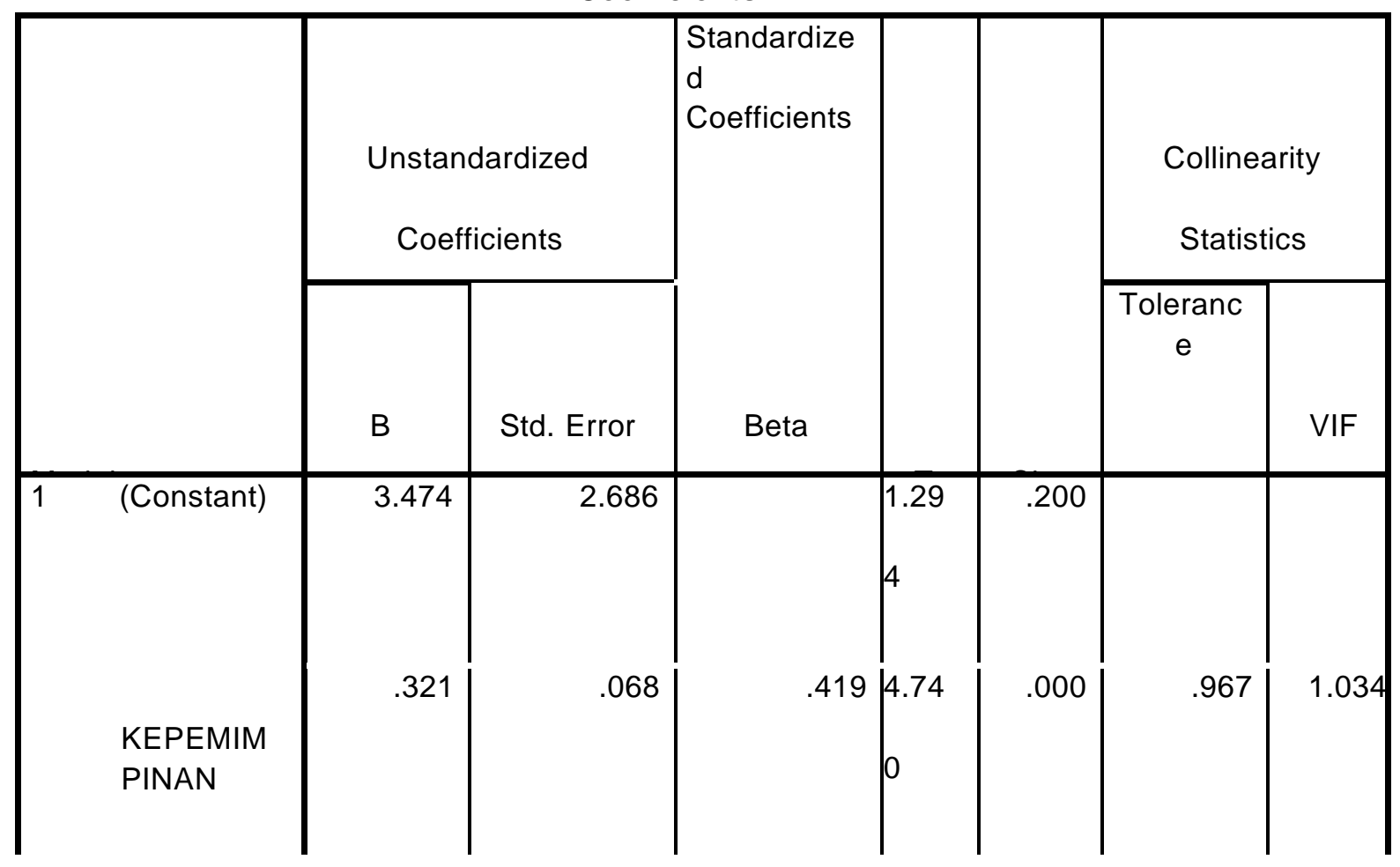


Analisis Pengaruh Kepemimpinan ...

\begin{tabular}{l|l|l|l|l|l|l|l|}
\hline \hline KOMPENS & .718 & .124 & .512 & 5.78 & .000 & .967 & 1.034 \\
ASI \\
FINANSIAL
\end{tabular}

\section{a. Dependent Variable: KEPUASAN KERJA}

Berdasarkan hasil perhitungan diatas, terlihat bahwa variabel kepemimpinan dan kompensasi finansial memiliki nilai $\mathrm{VIF}=1,034$ dan nilai Tolerance $>0,1$ sehingga dapat dinyatakan model regresi tidak terdapat masalah kolinieraritas.

\subsection{Uji Heteroskedastisitas}

Metode yang digunakan adalah melihat pola titik-titik pada scatterplots regresi yaitu dengan cara melihat grafik scatterplot antara standardized predicted value (ZPRED) dengan studentized residual (SRESID). Jika titik-titik menyebar dengan pola yang tidak jelas di atas dan di bawah angka 0 pada sumbu $Y$ maka disimpulkan bahwa tidak terjadi masalah heteroskedastisitas pada model regresi (Priyatno, 2010).

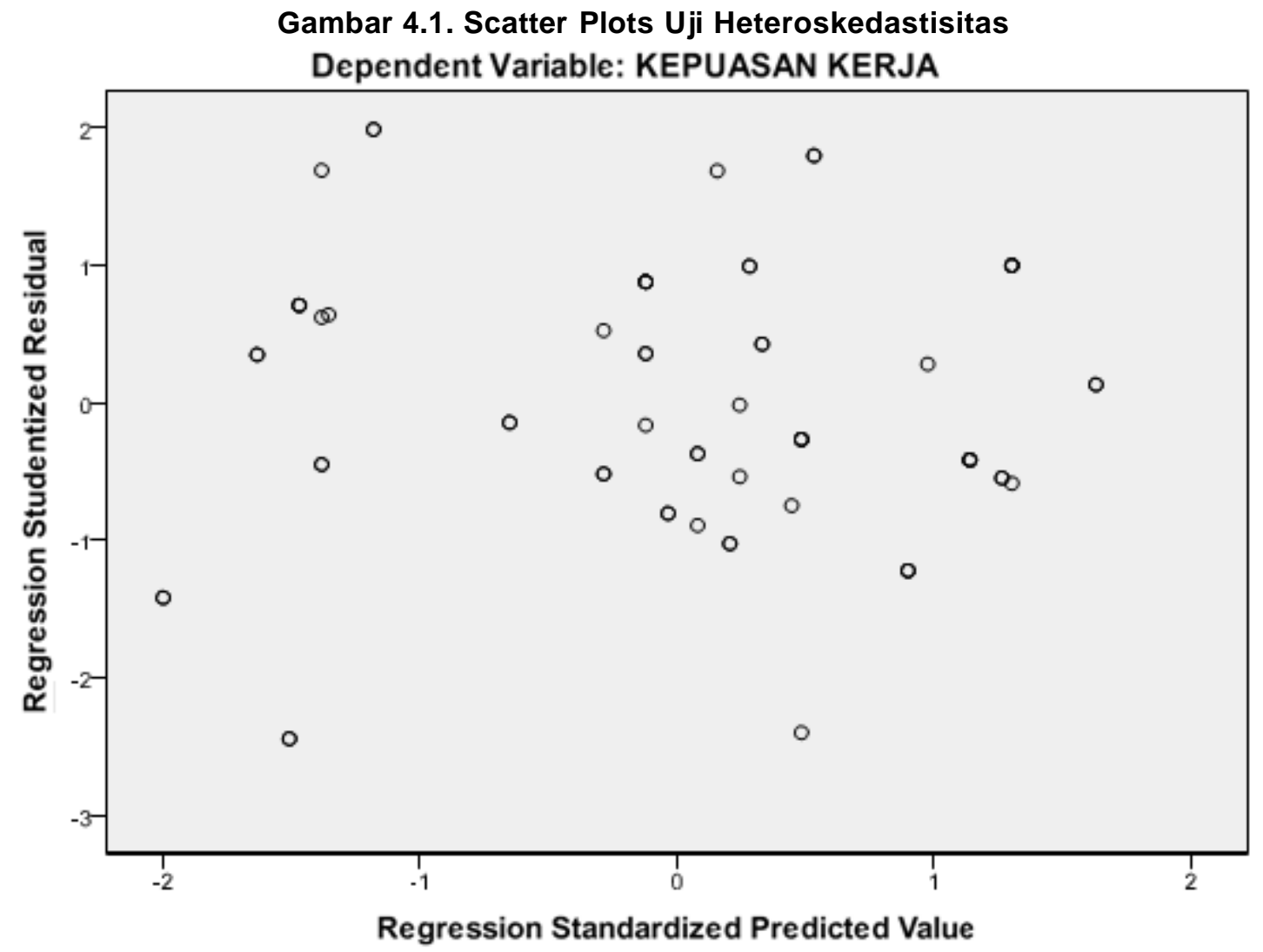

Berdasarkan gambar 4.1, dapat dilihat adanya pola yang tidak jelas serta titik-titik menyebar di atas dan di bawah angka 0 pada sumbu $Y$ sehingga dapat disimpulkan bahwa tidak terjadi heterokedastisitas pada model regresi ini, sehingga model regresi ini layak dipakai. 
Suatu data dapat dikatakan tidak memiliki gejala heterokedastisitas apabila signifkansinya $>0,05$. Agar uji heterokedastisitas dapat dikatakan lebih akurat, maka berikut tabel 4.5 hasil uji heterokedastisitas:

Tabel 4.5. Uji Heterokedastisitas Correlations

\begin{tabular}{|c|c|c|c|c|c|}
\hline & & & $\begin{array}{l}\text { Unstandardi } \\
\text { zed } \\
\text { Residual }\end{array}$ & $\begin{array}{l}\text { TOTAL_K } \\
\text { O }\end{array}$ & TOTAL_KP \\
\hline \multirow[t]{3}{*}{$\begin{array}{l}\text { Spearman's } \\
\text { rho }\end{array}$} & $\begin{array}{l}\text { Unstandardize } \\
\text { d Residual }\end{array}$ & $\begin{array}{l}\text { Correlation } \\
\text { Coefficient } \\
\text { Sig. } \\
\text { tailed) } \\
\mathrm{N}\end{array}$ & $\begin{array}{l}1.000 \\
67\end{array}$ & $\begin{array}{l}.014 \\
.913 \\
67\end{array}$ & $\begin{array}{l}-.062 \\
\\
.616 \\
67\end{array}$ \\
\hline & TOTAL_KO & $\begin{array}{l}\text { Correlation } \\
\text { Coefficient } \\
\text { Sig. (2- } \\
\text { tailed) } \\
\mathrm{N}\end{array}$ & $\begin{array}{l}.014 \\
.913 \\
67\end{array}$ & $\begin{array}{l}1.000 \\
67\end{array}$ & $\begin{array}{l}.223 \\
.070 \\
67\end{array}$ \\
\hline & TOTAL_KP & $\begin{array}{l}\text { Correlation } \\
\text { Coefficient } \\
\text { Sig. } \\
\text { tailed) } \\
\mathrm{N}\end{array}$ & $\begin{array}{l}-.062 \\
.616 \\
67\end{array}$ & $\begin{array}{l}.223 \\
.070 \\
67\end{array}$ & $\begin{array}{l}1.000 \\
67\end{array}$ \\
\hline
\end{tabular}

Dari tabel diatas dapat dilihat bahwa indikator dari setiap variabel memiliki signifikansi sebesar 0,913 dan 0,616 $(>0,05)$. Sehingga dapat dikatakan bahwa tidak terjadi heterokedastisitas pada model regresi di dalam penelitian ini.

\subsection{Analisis Model Regresi}

Analisis regresi berganda dilakukan peneliti untuk mengukur pengaruh antara variabel kepemimpinan (X1), kompensasi finansial (X2) sebagai variabel independent terhadap kepuasan kerja $(\mathrm{Y})$ sebagai variabel dependent.

\subsubsection{Pembahasan Model Regresi}

Berdasarkan hasil yang diperoleh dari tabel 4.6, maka dapat disusun suatu model regresi, sebagai berikut: 
Tabel 4.6. Model Regresi

\section{Coefficients $^{\mathrm{a}}$}

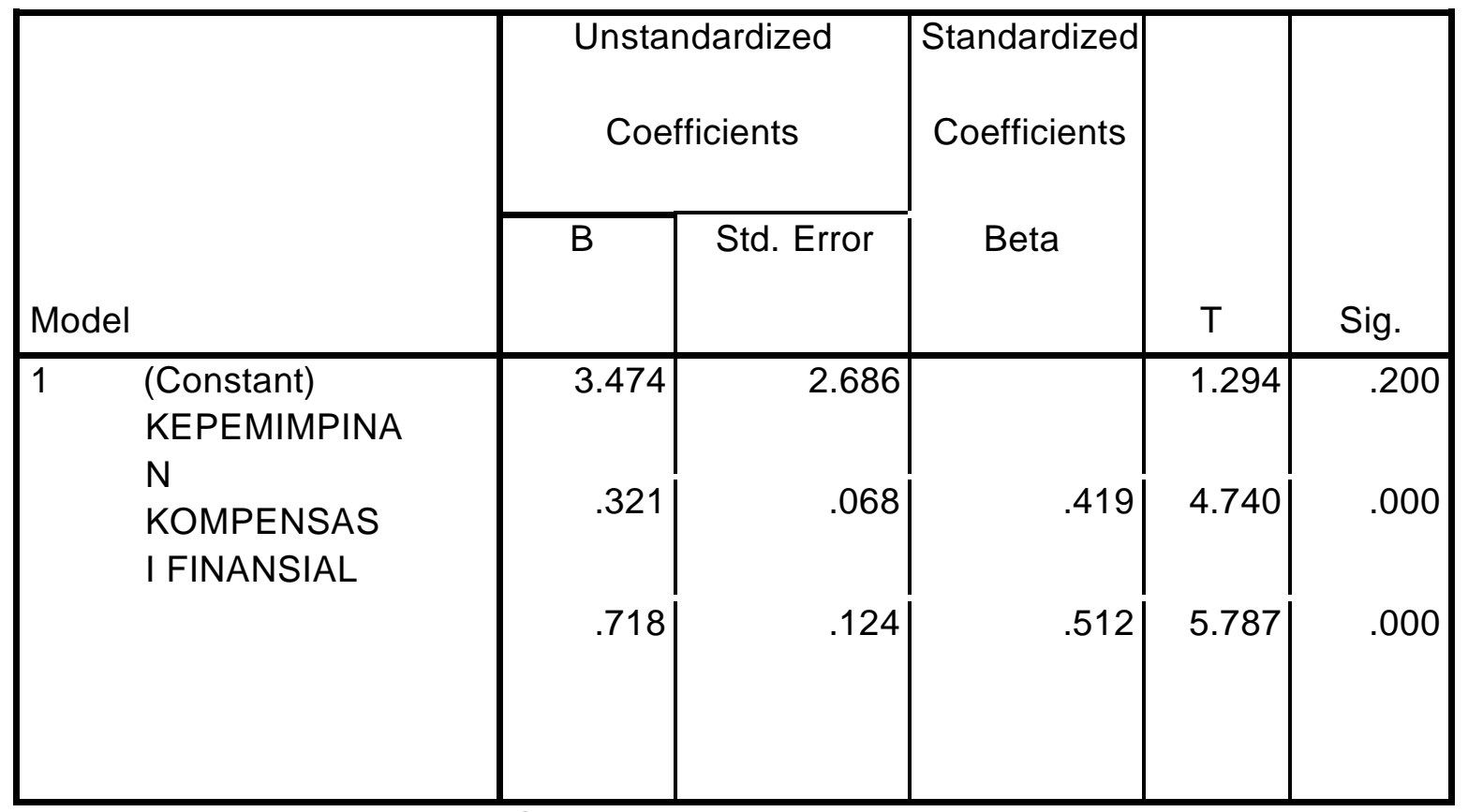

a. Dependent Variable: KEPUASAN KERJA

$\hat{Y}=\beta 0+\beta 1 X 1+\beta 2 X 2$

Kepuasan Kerja $=3.474+0.321$ Kepemimpinan +0.718 Kompensasi Finansial Keterangan:

$\mathrm{Y} \quad=$ Kepuasan Kerja

$\mathrm{X}_{1}=$ Kepemimpinan

$\mathrm{X}_{2}=$ Kompensasi Finansial

Kepemimpinan berpengaruh signifikan terhadap kepuasan kerja dengan koefisien regresi sebesar 0,321 dan menunjukkan hubungan yang searah terhadap kepuasan kerja, artinya kepemimpinan seseorang berpengaruh dalam meningkatkan kepuasan kerja karyawan.

Kompensasi Finansial berpengaruh signifikan terhadap kepuasan kerja dengan koefisien regresi sebesar 0,718 dan menunjukkan hubungan yang searah terhadap kepuasan kerja, artinya kompensasi finansial berpengaruh dalam meningkatkan kepuasan kerja karyawan.

Hal tersebut sesuai dengan penelitian terdahulu yang telah dilakukan oleh (Ruvendi, 2005) menemukan adanya hubungan dan pengaruh signifikan antara variabel imbalan dan kepemimpinan terhadap kepuasan kerja. 


\subsubsection{Uji T}

Uji T digunakan untuk mengetahui adanya pengaruh antara kepemimpinan dan kompensasi finasial secara parsial terhadap kepuasan kerja. Jika $p \geq 0,05$ maka $\mathrm{H}_{0}$ tidak dapat ditolak. Hasilnya dapat dilihat pada tabel 4.7 di bawah ini:

Tabel 4.7. Hasil Uji T

\section{Coefficients $^{\mathrm{a}}$}

\begin{tabular}{|c|c|c|c|c|c|c|}
\hline & & $\begin{array}{r}\text { Uns } \\
\mathrm{C}\end{array}$ & $\begin{array}{l}\text { dardized } \\
\text { icients }\end{array}$ & $\begin{array}{l}\text { Standardized } \\
\text { Coefficients }\end{array}$ & & \\
\hline & & B & Std. Error & Beta & & \\
\hline 1 & $\begin{array}{l}\text { (Constant) } \\
\text { KEPEMIMPINAN } \\
\text { KOMPENSASI } \\
\text { FINANSIAL }\end{array}$ & $\begin{array}{l}3.474 \\
.321 \\
.718\end{array}$ & $\begin{array}{l}2.686 \\
.068 \\
.124\end{array}$ & $\begin{array}{l}.419 \\
512\end{array}$ & $\begin{array}{l}1.294 \\
4.740 \\
5.787\end{array}$ & $\begin{array}{l}.200 \\
.000 \\
.000\end{array}$ \\
\hline
\end{tabular}

a. Dependent Variable: KEPUASAN KERJA

\subsubsection{Hipotesis}

Pada tabel 4.7 Hasil Uji T di atas hasil pengolahan data kuesioner yang disebarkan, maka dapat menarik kesimpulan untuk menentukan kebenaran hipotesis dari rerangka yang telah dibuat yaitu hipotesis 1 dan hipotesis 2 .

\section{a. Hipotesis 1}

$H_{0}$ 1: Kepemimpinan tidak berpengaruh signifikan dengan kepuasan kerja karyawan

$\mathrm{Ha}$ 1: Kepemimpinan berpengaruh signifikan dengan kepuasan kerja karyawan

Dari tabel diatas dapat dilihat bahwa kepemimpinan memiliki nilai signifikan sebesar $0,000<0.05$ sehingga keputusannya adalah Ho ditolak. Maka dapat dinyatakan bahwa terdapat pengaruh antara kepemimpinan terhadap kepuasan kerja. (Robbins,2006) mendefinisikan kepemimpinan adalah kemampuan untuk mempengaruhi kelompok menuju pencapaian sasaran. Jika sebuah organisasi memiliki seorang pemimpin dengan kemampuan memimpin yang kokoh maka karyawan akan merasa termotivasi dan bersemangat dalam menyelesaikan pekerjaanya, dengan begitu kepuasan kerja dalam diri karyawan akan tercipta sehingga suatu organisasi akan lebih efektif untuk mencapai sasaran tujuannya.

Hal ini diperkuat dengan penelitian yang dilakukan (Hamidifar, 2009) menemukan adanya hubungan dari setiap faktor-faktor kepemimpinan terhadap kepuasan kerja karyawan.

\section{b. Hipotesis 2}

$\mathrm{H}_{\mathrm{O}}$ 2: Kompensasi finansial tidak berpengaruh signifikan dengan kepuasan kerja karyawan $\mathrm{Ha}_{\mathrm{a}}$ 2: Kompensasi finansial berpengaruh signifikan dengan kepuasan kerja karyawan

Dari tabel diatas dapat dilihat bahwa kompensasi finansial memiliki nilai signifikan sebesar $0,000<0.05$ sehingga keputusannya adalah Ho ditolak. Maka dapat dinyatakan bahwa terdapat pengaruh antara kompensasi finansial terhadap kepuasan kerja. (Hasibuan, 2011) mendefinisikan kompensasi sebagai semua pendapatan yang 
Analisis Pengaruh Kepemimpinan ...

berbentuk uang, barang langsung atau tidak langsung yang diterima karyawan sebagai imbalan atas jasa yang diberikan kepada perusahaan. Jika seorang karyawan merasa imbalan yang mereka dapatkan sesuai dengan jasa yang telah mereka berikan kepada perusahaan maka akan timbul rasa kepuasan dalam diri karyawan dengan apa yang telah mereka kerjakan selama ini.

Hal ini diperkuat dengan penelitian yang dilakukan oleh (Fauzan, 2012) yang menyimpulkan bahwa secara parsial terdapat pengaruh yang signifikan antara kompensasi finansial dengan kepuasan kerja karyawan. Hasil analisis regresi antara kompensasi finansial (X1) terhadap kepuasan kerja pegawai $(Y)$ menunjukkan nilai $p$ $(\operatorname{sig} t)=0.001<0.05$. Ini berarti secara parsial ada pengaruh yang signifikan antara kompensasi finansial terhadap kepuasan kerja pegawai. Variasi perubahan nilai variabel dependen $(\mathrm{Y})$ yang dapat dijelaskan oleh variabel independen $(\mathrm{X} 1)$ sebesar $8.6 \%(\mathrm{r} 2=$ 0.086). Nilai koefisien regresi (B) yang diperoleh adalah positif yaitu 0.356 , dapat diartikan bahwa semakin tinggi kompensasi finansial, maka semakin tinggi pula kepuasan kerja pegawai, dengan asumsi variabel bebas lainnya konstan.

\section{PENUTUP}

\subsection{Kesimpulan}

Berdasarkan hasil analisis dan pembahasan mengenai pengaruh kepemimpinan dan kompensasi finansial terhadap kepuasan kerja karyawan pada PT Pertamina Lubricants, dapat ditarik kesimpulan sebagai berikut:

1. Berdasarkan dari hasil analisis, dapat disimpulkan bahwa variabel kepemimpinan memiliki pengaruh yang signifikan terhadap kepuasan kerja karyawan di PT Pertamina Lubricants.

2. Berdasarkan dari hasil analisis, dapat disimpulkan bahwa variabel kompensasi finansial memiliki pengaruh yang signifikan terhadap kepuasan kerja karyawan di PT Pertamina Lubricants.

\subsection{Saran}

Terkait pada hasil analisis yang menyatakan bahwa kepemimpinan dan kompensasi finansial berpengaruh signifikan terhadap kepuasan kerja karyawan, maka Penulis memberikan beberapa saran kepada PT Pertamina Lubricants, yaitu:

\section{A. Bagi Perusahaan}

1. Pemimpin yang ada di setiap cabang diharapkan mampu memberikan arahan serta dapat mengetahui segala kebutuhan dan masalah karyawan terkait dengan pekerjaan yang diberikan. Pemimpin harus mampu menentukan prioritas, karena prioritas tersebut akan membuat karyawan tahu dengan apa yang harus mereka kerjakan terlebih dahulu sehingga karyawan akan bekerja dengan lebih baik lagi dan kepuasan kerja karyawan pun tercapai.

2. Perusahaan harus memperhatikan sistem overtime yang ada, sistem overtime berhubungan dengan tarif gaji per jam lembur. Overtime biasanya dibayarkan kepada pegawai secara per jam, seberapa lama mereka bekerja lembur semakin besar bayarannya. Dalam arti, upah yang diberikan harus sesuai besarnya dengan 
seberapa lama karyawan bekerja lembur diluar jam kerja, karena hal ini akan berpengaruh terhadap hasil kerja yang karyawan berikan ke perusahaan.

\section{B. Bagi Penelitian Selanjutnya}

1. Penelitian selanjutnya diharapkan dapat memperluas mengenai kajian dan penelitian terdahulu yang berkaitan dengan penelitian ini.

2. Dalam penelitian selanjutnya diharapkan dapat mengidentifikasi faktor-faktor lain yang tidak diungkap dalam penelitian ini, yang berkaitan dengan hal-hal yang berpengaruh terhadap kepuasan kerja dan bangaimana cara meningkatkan kepuasan kerja itu sendiri.

\section{DAFTAR PUSTAKA}

Cherrington, J. David. (1995). The Management of Human Resource. New Jersey: Prentive Hall International.

Daft, Richard L. (2010). New Era of Management. Singapore: Cengage Learning

Davis, K. (1996). Perilaku Dalam Organisasi. Jilid 1 dan 2 (Terjemahan). Jakarta: Erlangga.

Efendi, T.M. (2005). Manajemen Sumber Daya Manusia. Edisi 3. Jakarta: Gramedia.

Fauzan, R. (2012). Pengaruh Kompensasi dan Karakteristik Pekerjaan Terhadap Kepuasan Kerja (Studi pada Staf Administrasi Universitas Tanjungpura, Pontianak). Volume 8 Nomor 2 Tahun 2012. Fakultas Ekonomi Universitas Tanjungpura. Pontianak.

Fiedler, F.E. (2000). Improving Leadership Effectiveness. New York: John Willey.

Ghozali, A. (2006). Aplikasi Analisis Multivariat dengan Program SPSS. Semarang: Badan Pustaka Universitas Diponegoro.

Gitosudarmo, I. Sudita, N. (1997). Perilaku Keorganisasian. Edisi 1. BPFE: Yogyakarta. Hamidifar, F. (2009). A Study of the Relationship Between Leadership Stylesand Employee Job Satisfaction at Islamic Azad University Branches in Tehran, Iran. Assumption University, School of Business.

Handoko, T.H. (2000). Manajemen Personalia dan Sumber Daya Manusia. Edisi 2. Yogyakarta: Penerbit BPFE.

Hasibuan, M.P. (2011). Manajemen Sumber Daya Manusia. Edisi Revisi. Penertbit PT. Jakarta: Bumi Aksara.

Kountour, R. (2000). Metode Penelitian. Seri Umum Nomor 5. Jakarta: Penerbit PPM.

Lok, P. Crawford, J. (2003). The Effect of Organisational Culture and Leadership Style on Job Satisfaction and Organisational Commitment (a Cross-National Comparison). Emerald Journal. School of Management New South Wales, Australia.

Malhotra, N.K. (2005). Riset Pemasaran. Jakarta: PT Indeks.

Mangkunegara, AA.P. (2000). Manajemen Sumber Daya Manusia. Bandung: Rosda Karya. 